\title{
DA TEORIA ECONÔMICA À PRÁTICA JURÍDICA: ORIGEM, DESENVOLVIMENTO E PERSPECTIVAS DOS INSTRUMENTOS TRIBUTÁRIOS DE POLÍTICA AMBIENTAL
}

\section{Eugênio Battesini}

\section{INTRODUÇÃO}

\section{Questão ambiental}

A concepção do meio ambiente como fonte inesgotável de recursos para a produção e depositário de subprodutos das atividades econômicas pautou a dinâmica de interação do homem com a natureza ao longo de séculos. Contemporaneamente, contudo, a crescente deterioração da capacidade de assimilação dos ecossistemas e da capacidade de regeneração dos recursos naturais em níveis compatíveis com o desgaste imposto pelas atividades econômicas vem demandando profunda revisão do tipo de relação que o homem mantém com a natureza. Definitivamente incorporada na agenda política e de pesquisas científicas ${ }^{3}$, a questão ambiental, materializada em fenômenos como mudanças climáticas, perda de biodiversidade, poluição do at e da água, conforme registra a Organização para Cooperação e Desenvolvimento Econômico ${ }^{2}$ - OCDE, constitui desafio fundamental neste início de século XXI.

\section{Abordagem interdisciplinar}

As relações entre atividade econômica e meio ambiente evidenciam-se complexas e multifacetárias e, em ambiente globalizado, permeadas por componente dinâmico,

1 Marcos institucionais relevantes são: a reunião científica do Clube de Roma no final da década de 1960, que resultou na publicação do relatório The limits to grow, em 1972; e a Conferência de Estocolmo sobre o Meio Ambiente, em 1972. Vejam-se sobre o tema: PEARCE, David W; TURNER, Kerry R. Economics of natural resources and the environment. Bibliografia: p. 23.

2. OCDE. Environmental outlook (2020). 
caracterizado pela elevada mobilidade de pessoas, bens, capitais e informações através do mundo. Em tal contexto, consoante destacam Hunter, Salzman e Zaelke ${ }^{3}$, impositiva a adoção de abordagem analítica interdisciplinar ${ }^{4}$. Abordagem que enfatize o diálogo e a cooperação científica entre as disciplinas de forma a alavancar a compreensão da questão ambiental, proporcionando perspectiva mais coerente e realista do que a proporcionada isoladamente por cada disciplina, bem como de forma a ampliar o leque conhecimentos e alternativas de atuação disponíveis. Relevante, pois, a análise integrativa direito/economia/ecologia com o intuito de captar o conjunto de fatores relevantes envolvidos na questão ambiental.

\section{Tributação ambiental}

$\mathrm{Na}$ esteira de tal paradigma, desenvolve-se o presente texto com o objetivo de vislumbrar relevante instrumento de preservação do meio ambiente, a tributação ambiental. A importância do tema proposto pode ser aferida a partir do fato de que a OCDE recomenda a utilização dos instrumentos tributátios de política ambiental a seus países membros ${ }^{5}$. A ênfase é atribuída ao estudo da origem, desenvolvimento e perspectivas, destacando-se o relevante papel desempenhado pela tributação ambiental na busca de desenvolvimento econômico sustentável.

\section{Metodologia exposição}

A exposição será efetivada adotando como referencial analítico o movimento denominado direito e economia, corpo de pensamento interdisciplinar que se valendo de linguagem preponderantemente econômica propugna, em essência, o estudo do direito e da economia em perspectiva sistêmica, ampliando a base analítica tradicional das duas ciências; do direito que passa a ser concebido não apenas como sistema de coerção, mas também como guia de conduta e mecanismo transmissor de preços implícitos, e da economia que passa a considerar o direito como elemento ativo, vislumbrando seu impacto sobre a dinâmica de funcionamento do sistema econômico ${ }^{6}$. O texto será dividido em duas partes: direito,

3 HUNTER, David; SALZMAN, James; ZAELKE, Durwood. International environmental law and policy. Bibliografia: p. 151.

4 Consoante lucidamente destaca Robert Costanza, a adoção de abordagem interdisciplinar não implica em alternativa a qualquer das disciplinas individualmente consideradas, mas sim em nova forma de vislumbrar os problemas científicos, forma que pode adicionar valor e suprir deficiências da abordagem unidisciplinar. Citado por: HUNTER, David; SALZMAN, James; ZAELKE, Durwood. International environmental law and policy. Bibliografia: p. 152.

${ }^{5}$ OCDE. Environment programme (2005-2006). Bibliografia: p. 18.

${ }^{6}$ A relevância e crescente reconhecimento do movimento de direito e economia são destacados de forma impar por Bruce Ackerman, que se referiu ao movimento como "o desenvolvimento mais importante do século XX no campo dos estudos legais", e Mercuro e Medema, que registram o fato 
economia e meio ambiente; e tributação ambiental. Na primeira parte serão desenvolvidos os tópicos: atividade econômica e desenvolvimento sustentável, destacando-se a origem econômica da tributação ambiental; e política ambiental, contextualizando-se a tributação ambiental no âmbito dos instrumentos de política ambiental. Na segunda parte a tributação ambiental será analisada quanto a aspectos teóricos e evidências empíricas.

\section{DIREITO, ECONOMIA E MEIO AMBIENTE}

\subsection{Atividade econômica e desenvolvimento sustentável}

\section{Escassez}

A dicotomia recursos naturais limitados e necessidades humanas ilimitadas conduz à noção de escassez, núcleo analítico da moderna ciência econômica. Sinalizada através do sistema de preços, a escassez determina a dinâmica de alocação de recursos no sistema econômico.

\section{Dinâmica mercado}

Sob a ótica microeconômica neoclássica (mainstream na ciência econômica), a dinâmica de mercado é estabelecida através da ação individual de agentes racionais, maximizadores de sua utilidade, mediante análise da relação custo/benefício marginal. A interação de agentes individuais determina oferta e demanda de mercado, estabelecendo o mecanismo de preços (indice de escassez) que contém o conjunto de informações necessárias e suficientes para o funcionamento racional do sistema econômico. Dito de outra forma, o mecanismo de preços proporciona a utilização eficiente dos recursos limitados na satisfação das necessidades humanas ilimitadas, conduzindo automaticamente a uma situação de equilíbrio ótimo no sentido de Pareto, situação na qual ninguém poderá melhorar seu bem-estar sem sacrifício do bem-estar de outrem.

de que "nas últimas décadas o movimento de direito e economia se desenvolveu de um pequeno e esotérico ramo de pesquisa com economia e direito para um substancial movimento que tem auxiliado a ambos, redefinindo o estudo do direito e expondo a economia às importantes implicaçóes do direito". Vejam-se, respectivamente: COOTER, Robert; ULEN, Thomas. Derecho y economia. Bibliografía: p. 13; e MERCURO, Nicholas; MEDEMA, Steven G. Economics and the law: from Posner to post-modernism. Bibliografia: preface, p. X. 


\section{Falhas mercado}

Quando algum fator externo não permite que o sistema de mercado funcione regularmente, conduzindo a que preços e quantidades de equilíbrio não sejam de equilibrio ótimo no sentido de Pareto, presentes se fazem falhas de mercado. Os problemas ambientais geralmente decorrem da existência de falhas de mercado. As principais falhas de mercado devem-se a existência de bens públicos e externalidades. $O$ fato de que certos bens sejam de livre acesso e de consumo não excludente conduz a sua sobre-utilização, determinando graves problemas ambientais como a extinção de espécies causada por pesca predatória (tragédia dos comuns). $O$ fato de que determinados custos de produção não sejam captados pelo sistema de preços de mercado, mas simplesmente repassados à sociedade, determina a ocorrência de graves problemas ambientais como a poluição do ar e da água, externalidades negativas?.

\section{Externalidades}

A existência de externalidades foi identificada na própria origem da abordagem neoclássica, nos escritos do economista inglês Alfred Marshall (Principles of economics 1890). Coube, contudo, a outro economista inglês, Arthur Cecil Pigou (The economics of welfare -1920), a formalização analítica do problema das externalidades e a proposição de mecanismo de correção de tais falhas de mercado, a tributação da atividade econômica geradora de externalidades. Considerando a jurisprudência inglesa do início do século XX, que normalmente não estabelecia o dever de indenização pelas empresas de transporte ferroviário dos danos causados pelos incêndios florestais ocasionados pelas faíscas emitidas pelas locomotivas, Pigou desenvolveu o raciocínio de que a não internalização de tais custos no processo produtivo conduz ao funcionamento ineficiente do mercado, face à existência de excesso de produção e oferta. Em outras palavras, a existência de uma lacuna de informação não refletida nos preços, representada pelos custos sociais caracterizados pelas externalidades, determina que o mercado opere além de sua fronteira de possibilidades de produção.

\section{Tributação ambiental}

A solução do problema ambiental gerado pelas externalidades, na perspectiva proposta por Pigou, passa pela ação reguladora do Estado mediante a imposição de tributo incidente sobre a atividade poluidora (aumento do custo de produção) que leve à redução no nível de atividade econômica (diminuição da quantidade demandada), de forma a corrigir o funcionamento ineficiente do mercado (economia volta a atingir situação ótima no sentido de Pareto). Em termos técnicos (figura 1), a tributação ambiental conduz à equalização dos custos

\footnotetext{
${ }^{7}$ As externalidades podem ser positivas, benefícios sociais não captados pelo sistema de preços, tais como os proporcionados pela educação e vacinação.
} 
matginais privado e social, mediante internalização dos custos marginais externos representados pela poluição $(\mathrm{CMg}+\mathrm{CMgE}=$ $\mathrm{CMgS}$ ), determinando que a economia volte a atingir o equilíbrio ótimo no sentido de Pareto (aumento de preço de $\mathrm{P} 1$ para $\mathrm{P}^{*}$ e redução da quantidade de $Q_{1}$ para $Q^{*}$ ). Sob tal perspectiva, vislumbra-se ser a tributação ambiental instrumento econômico que contribui duplamente para a preservação do meio ambiente, mediante diminuição dos níveis de poluição e mediante utilização menos intensa dos tecursos naturais.

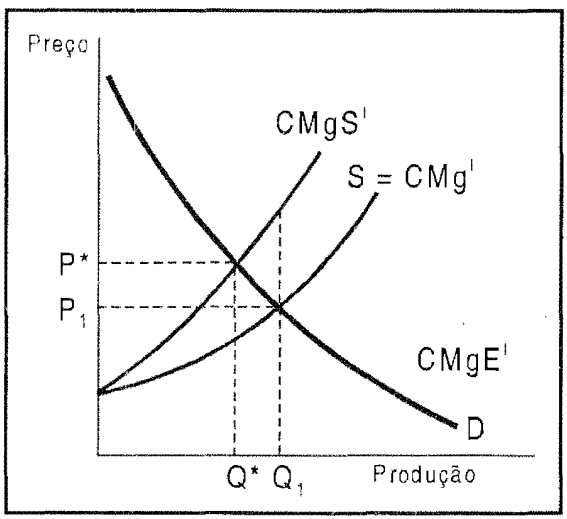

Figura 1 - Correção externalidades via tributação ${ }^{8}$.

Quando há externalidades negativas, o custo marginal social CMgS é maior que o custo marginal privado $\mathrm{CMg}$, sendo a diferença o custo marginal externo $\mathrm{CMgE}$. A economia opera de forma ineficiente, com equilibrio ocorrendo com preço P1 e quantidade Q1. A correção das externalidades ocorre com a internalização do custo marginal externo, mediante imposição de tributo equivalente à diferença entre $\mathrm{P}^{*} \mathrm{e} \mathrm{P} 1$, que conduz à redução da quantidade demandada em nível equivalente a diferença entre Q1 e Q*, determinando que a economia passe a atuar em nível ótimo no sentido de Pareto, com o equilíbrio ocorrendo com preço $\mathrm{P}^{*}$ e quantidade $\mathrm{Q}^{*}$.

\section{Nível ótimo poluição}

Outra derivação da abordagem analítica neoclássica diz respeito à noção de que é por demais oneroso para a sociedade a eliminação completa da poluição. A eficiência alocativa, nivel ótimo de poluição, é atingida quando os custos marginais de controle são iguais aos benefícios marginais de degradação ambiental (figura 2).

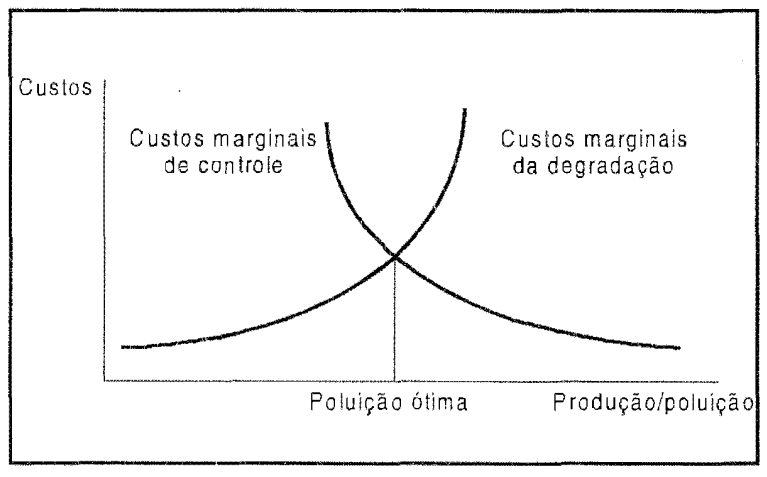

Figura 2. Nível de poluição ótima9

\footnotetext{
${ }^{8}$ Adaptado de: PINDYCK, Robert S.; RUBINFELD, Daniel L. Microeconomia. Bibliografia: p. 703.

"Adaptado de: MAY, Peter H. (org). Economia do meio ambiente. Bibliografia: p. 11.
} 


\section{Direitos propriedade e custos transação}

Estabelecida a lógica de que a poluição representa um custo de produção não computado pelo sistema de mercado, solução distinta da proposta por Pigou foi sugerida pelo economista norte-americano Ronald Coase (The problem of social cost -1960). Coase sustentou não ser necessário tributar a atividade produtiva poluidora, pois, desde que haja clara definição dos direitos de propriedade e desde que os custos de transação sejam nulos, as partes envolvidas estabelecem processo de negociação dos danos causados pela poluição de forma a atingir solução eficiente de mercado. De acordo com tal proposição, conhecida como teorema de Coase, em condições ideais a negociação proporciona a internalização dos custos de poluição de maneira mais eficaz do que a tributação. Em condições ideais de perfeita definição de direitos de propriedade e custos de transação nulos, maximiza-se a riqueza, chega-se à situação de equilíbrio ótimo de Pareto sem a necessidade de ação reguladora do Estado. Ocorre que, conforme destaca o próprio autor, em realidade, os direitos de propriedade normalmente não são claramente definidos e os custos de transação (informação, contratação, enforcement...) não são nulos. Em tal contexto, evidencia-se relevante a estruturação do sistema jurídico: de forma a propiciar condições para que se desenvolva o processo de negociação; de forma a dar efetividade à negociação acordada; de forma a que se obtenha solução arbitrada em caso de impasse ou impossibilidade de negociação. Assim sendo, sob tal ótica, a solução de problemas ambientais passa sim ação do Estado, não via tributação, mas sim mediante eficaz configuração do sistema jurídico. Expandindo o raciocínio, na ótica de Coase, a adequada estruturação do arcabouço legal é fundamental para o funcionamento eficiente do sistema econômico como um todo, pois as noções de direito de propriedade e de custos de transação, inerentes à atividade econômica, não são determinadas no plano econômico, mas sim no plano jurídico. Célebre é a manifestação de Coase no sentido de que "fazer economia sem entender o papel desempenhado pelo direito é algo que se assemelha ao estudo da circulação do sangue sem. ter um corpo... O sistema legal tem profundo efeito no funcionamento do sistema econômico e pode-se dizer que em certos aspectos o controla" ${ }^{1011}$.

\section{Desenvolvimento sustentável}

Sob outra perspectiva, relevante ampliar o foco da questão ambiental: vislumbrando a temática da alocação de recursos econômicos escassos no longo prazo; incorporando à análise a questão intergeracional; e considerando controvérsias acerca da relação entre

10 Vejam-se: MERCURO, Nicholas e MEDEMA, Steven G. Economics and the law: From Posner to PostModernism. Bibliografia: p. 172.

${ }^{11}$ Consoante registrou Coase ao receber o prêmio Nobel de economia em 1991, dado o reconhecimento da "crucial importância do sistema legal" é fácil compreender o florescimento do campo de estudos denominado "law and economics". COASE, Ronald H. The institutional structure of production. Bibliografia: p. 6. 
crescimento econômico e sustentabilidade meio ambiente. A expansão das atividades econômicas esbarta nas limitações do meio ambiente em dar suporte às atividades econômicas. Surge, pois, a noção de desenvolvimento sustentável ${ }^{12}$, que, em essência, vincula-se à idéia de satisfação das necessidades atuais sem comprometer a habilidade de satisfazer as necessidades futuras. O princípio do desenvolvimento sustentável foi formalizado na Conferência da Organização das Nações Unidas sobre o Meio Ambiente e Desenvolvimento - RIO 92, nos seguintes termos: "o direito ao desenvolvimento deve ser realizado de modo a satisfazer as necessidades relativas ao desenvolvimento e ao meio ambiente das gerações presentes e futuras" (princípio $3^{\circ}$ ).

\section{Economia meio ambiente}

A noção de desenvolvimento sustentável, concretizada em fatores como a preocupação com a não ocorrência de efeitos irreversíveis ao meio ambiente e a preservação da capacidade de assimilação e de regeneração do meio ambiente, serve de base para o que se convencionou chamar economia do meio ambiente, a qual comporta, basicamente, duas vertentes teóricas; economia ambiental e economia ecológica.

\section{Economia ambiental}

Prolongamento do mainstream neoclássico, a economia ambiental tem como pressuposto que o mecanismo de auto-ajuste dos mercados automaticamente promove a proteção ambiental, o que ocorre através do sistema de preços, que atua como indicativo da degradação ambiental e a corrige. A concepção básica é no sentido de que recursos naturais não representam limite absoluto à expansão da atividade econômica. O progresso científico e tecnológico permite que sejam superadas indefinidamente as restrições relativas representadas pela disponibilidade de recursos naturais (figura 3). A idéia subjacente é de que o investimento feito pelas gerações passadas e presente compensa as gerações futuras pelas perdas causadas pelo consums e produção pretérito e atual. Em tal contexto, o papel do Estado restringe-se a correção das falhas de mercado, pois a ação racional dos agentes econômicos determina dinâmica intertemporal eficiente de alocação de recursos escassos, conduzindo ao desenvolvimento sustentável.

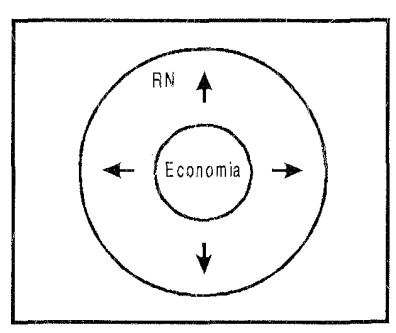

Figura 3 - Economia ambiental ${ }^{13}$

${ }^{12}$ A noção de sustentabilidade da atividade econômica não é nova. A idéia de que há limites naturais ao crescimento remonta a Thomas R. Malthus (An essay on the principle of population as it affects the future improvement of society - 1798), que enfatizou o rápido crescimento populacional, e a David Ricardo (On the principles of political economy and taxation - 1817), que enfatizou a limitaça dos recursos naturais.

${ }^{13}$ Adaptado de: MAY, Peter H. (org.). Economia do meio ambiente. Bibliografia: p. 8. 


\section{Economia ecológica}

Visão distinta é externada pela economia ecológica, que concebe o sistema econômico como um subsistema de um todo maior que o contém, impondo restrição absoluta à sua expansão (frgura 4). O progresso científico e tecnológico, mesmo sendo visto como ferramenta fundamental para aumentar a eficiência alocativa (motivo pelo qual deve ser fomentado), não é capaz de propiciar a superação indefinida dos limites ambientais. No longo prazo, a sustentabilidade do sistema econômico não é possível sem a estabilização dos níveis de consumo em patamares compativeis com a capacidade de carga do planeta. $O$ sistema econômico deve, pois, ter seus limites fixados pela sociedade, via ação reguladora do Estado. Em tal contexto, o papel do Estado adquire maior relevo, competindo-lhe, com base em considerações econômicas, éticas e morais, decidir acerca da utilização dos recursos naturais de forma proporcionar o desenvolvimento sustentável.

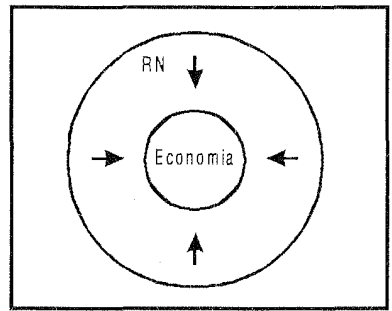

Figura 4 - Economia ecológica ${ }^{14}$

\section{Meio ambiente e regulação}

Em suma, no atual estágio de estudo da questão ambiental, conforme destacam Hunter, Salzman e Zaelke ${ }^{15}$, não mais se discute a necessidade ou não de regulação. Esta se faz necessária, seja para corrigir falhas de mercado (visão ortodoxa) ou para promover a estabilização dos níveis de consumo em patamares compatíveis com a capacidade de carga do planeta (visão heterodoxa). A questão que se coloca diz respeito à extensão, ao grau de regulação da atividade econômica com vistas ao atingimento do desenvolvimento sustentável. O que conduz ao necessário estudo da política ambiental e dos instrumentos de política ambiental, aspectos que se passa a considerat.

\subsection{Política ambiental}

\section{Caracterização política ambiental}

A noção de política ambiental encontra-se associada ao conjunto de meios e instrumentos, e sua forma de utilização, que objetivam reduzir o impacto negativo da ação humana sobre o meio ambiente. A política ambiental evidencia-se necessátia para a introdução ou adoção de posturas e procedimentos menos agressivos ao meio ambiente, tendentes ao desenvolvimento sustentável.

${ }^{14}$ Adaptado de: MAY, Peter H. (org.). Economia do meio ambiente. Bibliografia: p. 11.

${ }^{15}$ HUNTER, David; SALZMAN, James; ZAELKE, Durwood. International environmental law and policy. Bibliografia: p. 127. 


\section{Dimensões política ambiental}

Os problemas ambientais encontram-se, com freqüencia, testritos à esfera de uma nação, decortendo, pois, a formulação de programas de política ambiental de âmbito nacional. Contudo, em muitas de suas dimensões a questão ambiental transcende o interesse de países específicos, assumindo contornos internacionais. Problemas ambientais como a depleção de espécies migratórias e recursos vivos comuns (extinção de espécies animais e vegetais...), a poluição trans-fronteiriça do ar e recursos hídricos (vazamento de radioatividade, chuva ácida...) e a degradação global do meio ambiente (aquecimento global, mudanças climáticas...) vão além do interesse de países específicos. Em tal contexto, adquire relevo o papel desempenhado pela Organização das Nações Unidas, pela Organização para Cooperação ¿ Desenvolvimento Econômico, pelo Banco Mundial e por diversas outras instituições internacionais. Na busca do desenvolvimento sustentável, revela-se fundamental a atuação de tais entidades na formulação e implementação de programas de política ambiental de alcance global. Decisivos, também, a fixação de diretrizes e o estabelecimento de normas internacionais destinadas a regular a utilização dos recursos naturais comuns e a geração de externalidades internacionais causadas pelo transporte de mercadorias (acidentes como o vazamento de óleo mineral...), por processos e métodos de produção (emissão de substâncias tóxicas como o dióxido de enxofre...) e pelo uso/consumo de produtos nocivos ao meio ambiente (consumo de produtos que contribuem para a redução da camada de ozônio...).

\section{Instrumentos política ambiental}

Os instrumentos de política ambiental disponíveis às entidades nacionais e internacionais podem ser agrupados em três categorias ${ }^{16}$ : instrumentos legais; instrumentos econômicos; e instrumentos de comunicação e persuasão moral. Esclarecimento necessário é realizado por Faure ${ }^{17}$, que registra que a terminologia instrumentos legais/econòmicos deve ser relativizada, eis que todos os instrumentos econômicos são viabilizados via sistema jurídico e todos os instrumentos jurídicos produzem efeitos econômicos.

\section{Instrumentos legais}

Os instrumentos legais, também denominados instrumentos de comando-controle ou de regulação direta, implicam no controle direto sobre a atividade danosa ao meio ambiente. Controle realizado através do estabelecimento de normas, procedimentos e padrões a serem observados pelos agentes poluidores, bem como do estabelecimento de penalidades em

\footnotetext{
${ }^{16}$ Veja-se sobre o tema: MAY, Peter H. (org.). Economia do meio ambiente. Bibliografia: p. 142.

${ }^{17}$ FAURE. Michael G. Environmental regulation. Bibliografia: p. 444.
} 
caso de descumprimento. Exemplos de instrumentos legais são: normas de controle ou proibição de produtos; normas de controle ou proibição de processos de produção; normas de controle ou restrição de atividades poluidoras; o estabelecimento de especificações tecnológicas; o controle do uso de recursos naturais; o estabelecimento de padrões (nível ótimo), de quotas de poluição para fontes poluidoras específicas; normas definidoras dos direitos de propriedade (zoneamento ambiental, first-use doctrine); a responsabilização civil; e a responsabilização criminal.

\section{Instrumentos econômicos}

Os instrumentos econômicos, também denominados instrumentos de mercado ou de regulação indireta, implicam na geração de incentivos, considerados mediante análise da relação custo-benefício. Exemplos de instrumentos econômicos são: a tributação ambiental; a concessão de subsídios; a criação de mercados de transferência de quotas de poluição (sistema de permissões transferíveis); e a criação de mercado de reciclagem de resíduos.

\section{Instrumentos comunicação/coerção moral}

Os instrumentos de comunicação/coerção moral dizem respeito a mecanismos utilizados para conscientizar e informar os agentes poluidores e as populações afetadas sobre diversos temas ambientais, tais como; danos ambientais, atitudes preventivas, produtos $\mathrm{e}$ tecnologias menos agtessivas ao meio ambiente. Objetivam facilitar a cooperação entre agentes sociais na busca de soluções para os problemas ambientais. Exemplos de instrumentos de comunicação/coerção moral são: o marketing ambiental (divulgação e publicidade); o fornecimento de informações (educação ambiental); e os selos ambientais (certificação).

\section{Escolha instrumentos}

O Programa das Nações Unidas para o Meio Ambiente ${ }^{18}$ destaca que os complexos problemas ambientais da sociedade contemporânea demandam a utilização combinada dos instrumentos de política ambiental. De acordo com o organismo da ONU, a busca do desenvolvimento econômico sustentável requer a formulação de um mix de políticas que alcance os mais diversos setores da sociedade. Também na doutrina, registra Foure ${ }^{19}$, há convergência no sentido da combinação dos diversos instrumentos de política ambiental, com a atribuição de maior ênfase a determinado instrumento, de acordo com a especificidade

\footnotetext{
18. UNEP. Global Environment Outlook (GEO 1).

${ }^{19}$ FAURE. Michael G. Environmental regulation. Bibliografia: p. 459.
} 
do problema ambiental que se objetive enfrentar. Convergente também é o entendimento de que a tributação ambiental constitui consistente instrumento de política ambiental. Relevante, pois, avançar no estudo de tal instituto, vislumbrando-se aspectos teóricos e evidências empíricas.

\section{TRIBUTAÇÃO AMBIENTAL}

\subsection{Aspectos teóricos}

\section{Objetivo econômico}

A idéia básica inerente à tributação ambiental é de que a taxação da atividade poluidora atribuirá um preço à poluição, um custo que será considerado pela empresa poluidora no cálculo do preço do produto. Ônus que afeta a dinâmica de funcionamento de mercado, reduzindo o nível de atividade poluidora, bem como atua como força motriz, incentivo para o desenvolvimento de novas tecnologias. Vislumbra-se, pois, que a tributação ambiental possui objetivo econômico perfeitamente definido, alterat o comportamento poluidor.

\section{Extrafiscalidade}

O propósito de inibir comportamento difusamente indesejável caracteriza o caráter essencialmente extrafiscal da tributação ambiental. Ao objetivo de arrecadação de recursos para o custeio de despesas públicas sobrepõe-se o objetivo de racionalização da atividade econômica, conduzindo-a a resultados condizentes com a noção de desenvolvimento sustentável.

\section{Princípio poluidor paga}

A lógica de impor encargo ao poluidor, ínsita à pioneira formulação econômica de Pigou, dá origem ao princípio do poluidor paga, amplamente disseminado em direito ambiental e expressamente consagrado na Conferência RIO 92. O princípio 16 da Declaração do Rio de Janeiro estipula que "as autoridades nacionais devem esforçar-se para promover a internalização dos custos de proteção do meio ambiente e o uso de instrumentos econômicos, levando-se em conta o conceito de que o poluidor deve, em princípio assumir o custo da poluição, tendo em vista o interesse do público, sem desvirtuar o comércio e investimentos internacionais". 


\section{Critérios tributação ambiental}

No âmbito da Conferência RIO-92 também foran estipulados critérios para o estabelecimento de tributos ambientais, quais sejam: eficiência no plano da prevenção aos danos ambientais e exploração desequilibrada dos recursos naturais; eficiência do ponto de vista econômico, ou seja, na ponderação custo/benefício a arrecadação deve superar os custos de arrecadação; eficiência do ponto de vista administrativo, com o dispêndio de poucos recursos para sua arrecadação; e neutralidade, não repercussão negativa no comércio interno e externo.

\section{Modalidades tributação ambiental}

A tributação ambiental pode ser efetivada de diferentes formas. Adotando linha analítica traçada por Nicolaisen, Dean e Hoeller ${ }^{20}$, vislumbra-se que as principais modalidades de tributação ambiental são; tributação sobre o produto, tributação sobre a carga poluente e imposição de taxas administrativas.

\section{Tributação produto}

A tributação ambiental incidente sobre produtos adota como fato gerador a produção ou o consumo de cada unidade gerada de forma prejudicial ao meio ambiente (ex.: tributo incidente sobre o refino ou consumo de combustíveis fósseis). A tributação sobre o produto pode se dar de forma linear, guardar correspondência com a efetiva poluição gerada pela produção (modalidade que mais se aproxima da formulação original proposta por Pigou equalização custo marginal social com benefício marginal social), ou não linear, sem correspondência direta com a carga poluente.

\section{Tributo carga poluente}

A tributação ambiental incidente sobre a carga poluente adota como fato gerador a emissão de substâncias nocivas ao meio ambiente (ex.: tributo incidente sobre a emissão de substâncias tóxicas durante o processo produtivo). Tal modalidade de tributação pode considerar a carga poluente efetiva ou potencial, pré-estabelecida de acordo com as características da atividade econômica desenvolvida.

\footnotetext{
20 NICOLAJSEN, Joa; DEAN, Andrew; HOELLER, Peter. Economics and the environment: a survey of issues and police options. Bibliografia: p. 20.
} 


\section{Taxas administrativas}

As taxas administrativas vinculam-se ao exercício do poder de polícia ou à utilização, efetiva ou potencial, de serviços públicos em matéria ambiental (ex.: taxa de licenciamento para a realização de atividade econômica potencialmente poluente). Tais tributos não guardam relação necessária com o nível efetivo ou potencial de poluição.

\section{Aspectos positivos}

Consoante destaca Groosman ${ }^{21}$, claras vantagens podem ser apontadas na utilização dos instrumentos tributários de política ambiental. Entre os aspectos positivos destacamse: atuar como elemento indutor do desenvolvimento de novas tecnologias de produção que reduzam a poluição ou proporcionem o uso mais racional de recursos naturais que se pretenda conservar; tratar-se de instrumento dinâmico, eis que de permite o célere ajustamento dos parâmetros de tributação aos objetivos ambientais estabelecidos; o fato de que quando não é economicamente viável tributar a atividade produtiva é possível taxar o consumo dos produtos; proporcionar liberdade de escolha às empresas poluidoras, permitindo que elas optem pela utilização de tecnologias de produção que reduzam os níveis de poluição ou pelo dimensionamento de seus níveis de produção de forma a regular seus níveis de poluição; além do que, não obstante seu objetivo primário seja a redução dos níveis de poluição, como objetivo secundário induzido tem-se a geração de recursos públicos que podem ser utilizados para o financiamento de projetos ambientais.

\section{Aspectos negativos}

A utilização dos instrumentos tributários de política ambiental apresenta desvantagens. Entre os aspectos negativos podem ser referidos: produzir desvantagens comparativas entre as nações (ex.: empresas podem decidir realocar suas plantas industriais para países que não adotam a tributação ambiental); em mercados monopólicos ou cartéis os custos podem ser simplesmente repassados aos consumidores, sem a geração de incentivos para reduzir o impacto ambiental; proporcionarem incertezas no plano macro e microeconômico, afetando a tomada de decisão das empresas; afetar outtas variáveis sócioeconômicas tais como o nível de emprego e desenvolvimento regional; ter pouco alcance no que diz respeito a questões intergeracionais relativas ao esgotamento de recursos naturais; pode ser alternativa contraproducente nas hipóteses em que a reparação/compensação do dano ambiental represente custo menor; apresenta limitações práticas de implementação face às dificuldades inerentes à medição e controle da carga poluente; e elevados custos administrativos de fiscalização e arrecadação.

${ }^{21}$ GROOSMAN, Britt. Pollution tax. Bibliografia: p. 558. 


\subsection{Evidências empíricas}

\section{Tendência mundial}

A partir da Conferência RIO-92, vislumbra-se tendência mundial na utilização dos instrumentos tributários de política ambiental. Consoante destaca a OCDE, ao longo da década de 1990 todos seus países membros adotaram instrumentos tributários de política ambiental ${ }^{22}$.

\section{Vanguarda européia}

A União Européia ocupa posição de vanguarda em termos de tributação ambiental. Desde a década de 1950 discute-se a implantação de tributo único sobre energia, cujo objetivo seria estimular a adoção de fontes de energia de baixo impacto ambiental (energia eólica, solar...) em detrimento de fontes energéticas altamente agressivas ao meio ambiente (combustíveis fósseis, energia nuclear...). Não obstante tratar-se de tributo que disporia de base ampliada, eis que todos os produtos necessitam energia para sua fabricação, e cujo processo de artecadação seria simplificado, não foi adotado por implicar em sensível perda de competitividade global dos produtos europeus.

\section{Evidências Europa}

Diversas e bem sucedidas são as experiências européias. A tributação sobre emissão de efluentes e consumo de água tratada é realizada desde 1964 na França, sendo adotada também pela Alemanha, Holanda e Itália. A tributação incidente sobre produtos que proporcionam a contaminação do ar (combustíveis fósseis...) é efetivada na França desde 1989, sendo realizada também na Holanda, Noruega e Suécia. A tributação incidente sobre o lixo (embalagens plásticas, material de construção...), em especial resíduos industriais não biodegradáveis (óleos lubrificantes...) é realizada na Alemanha, Bélgica, Dinamarca, França, Holanda, Itália, Noruega e Suécia. Atividades geradoras de poluição sonora são tributadas na Alemanha, França, Holanda, Reino Unido e Suíça. Outras experiências eutopéias, sobretudo no campo das taxas administrativas, são verificadas na Áustria, Espanha, Finlândia, Grécia, Hungria, Irlanda, Islândia, Polônia e Portugal.

22 OCDE. Environmentally related taxas in OECD countries. 


\section{Evidências Estados Unidos}

Nos Estados Unidos vislumbra-se a tributação ambiental incidente sobre o refino de petróleo e sobre indústrias químicas potencialmente poluidoras. Outra modalidade é a imposição de adicional de imposto de renda para empresas que provoquem danos ambientais, bem como a redução da base de cálculo do mesmo imposto fara quem fizer doações com finalidade de preservação ambiental. Outra particularidade do sistema norte-americano é a constituição de um fundo, superfund, cujos recursos são destinados à reparação de danos ambientais.

\section{Evidências demais países OCDE}

A $O C D E^{23}$ registra outras experiências de tributação de atividades poluidoras do ar e água, atividades geradoras de lixo e de poluição sonora, além de taxas administrativas, entre seus países membros (não referidos nos parágrafos anteriores), podendo-se destacar Austrália, Canadá, Coréia do Sul, Japão, México, Nova Zelândia e Turquia.

\section{Evidências Brasil}

No Brasil, consoante registra $\mathrm{Nunes}^{24}$, a existência de sistema tributário comparativamente mais rígido conduz a que a contribuição dos instrumentos tributários na preservação ambiental seja modesta na comparação com outros países. Contudo, experiência positiva e sui generis é a taxa de preservação ambiental cobrada de turistas que visitam o atquipélago de Fernando de Noronha. Instituída pela Lei estadual de Pernambuco n 10.403 / 89, artigo 83, a taxa de preservação ambiental tem por hipótese de incidência o trânsito e permanência de pessoas no arquipélago, tendo por finalidade a promoção da preservação ambiental do arquipélago. Após extensiva avaliação, Nunes $^{25}$ destaca que tal modalidade tributária não tesiste à análise tributária clássica, sistema de tipologia fechada do fato jurídicotributário, registrando, contudo, que considerando sistema de tipologia aberta, calcado na motivação das normas jurídico-tributárias à luz de valores éticos e morais, a cobrança da taxa em comento é perfeitamente admissível à medida que calcada na busca do desenvolvimento sustentável, da preservação do meio ambiente único de Fernando de Noronha para as gerações futuras.

${ }^{23}$ OCDE. Environmentally related taxas in OECD countries.

${ }^{24}$ NUNES, Cleucio Santos. Direito tributário e meio ambiente. Bibliografia: p. 187.

${ }^{25}$ Idem. Bibliografia: p. 184. 


\section{CONCLUSÃO}

\section{Perspectivas tributação ambiental}

Não obstante sua consistência teórica, o grande desafio da tributação ambiental tem sido no campo da implementação, da transposição do plano abstrato para o mundo real de forma a proporcionar resultados tangíveis. O êxito da experiência preservacionista de Fernando de Noronha e as evidências empíricas advindas dos países vinculados à OCDE são indicativos do relevante papel destinado aos instrumentos tributários de política ambiental na busca do desenvolvimento sustentável.

\section{Desafio desenvolvimento sustentável}

Resta, contudo, longo caminho a ser trilhado. Nesse sentido, recomendável a adoção de abordagem analítica interdisciplinar, de forma a potencializar a compreensão da questão ambiental. Necessária a combinação de instrumentos econômicos, legais e de comunicação/ persuasão moral na implementação de políticas ambientais. Imperiosa a formulação de políticas ambientais que considerem não apenas fatores de ordem econômica e jurídica, mas, sobretudo, sejarn calcadas em valores éticos e morais, inafastáveis ao se cogitar da relação intergeracional inerente ao desenvolvimento sustentável.

\section{OBRAS CONSULTADAS}

AMARO, Luciano. Direito tributário brasileiro. São Paulo: Editora Saraiva, 1998. $2^{2}$ edição.

BAUMOL, Willian J.; OATES, Wallace E. The theory of environmental polyce. $2^{a} \mathrm{ed}$. Cambridge: Cambridge University Press, 1988.

BENJAMIN, Antônio Herman; SÍCOLI, José Carlos Meloni. O futuro da poluição e da implementação ambiental. São Paulo: IMESP, 2001. 633 p.

BYRNS, Ralph T.; STONE Jr., Gerald W. Microeconomia. São Paulo: Makron, 1996.

COASE, Ronald H. The problem of social cost. Publicado em: Economic foundations of private law. Organizado por: POSNER, Richard A.; PARISI, Francesco. Cheltenham: Elgar Critical Writings Reader, 2002.669 p.

The institutional structure of production. Nobel lecture. Dez. 2002. Disponivel em : <nobelprize.org>. Acesso em: 17 mai. 2005.

COÊLHO, Sacha Calmon Navarro. Curso de direito tributário brasileiro. Rio de Janeiro: Editora Forense, 2000. $5^{\mathrm{a}}$ edição. 
COLOMA, German. Analisis economico del derecho. Buenos Aires: Ciudad Argentina, $2001.306 \mathrm{p}$.

COOTER, Robert; ULEN, Thomas. Derecho y economia. Tradução: Eduardo L. Suárez. México: Fondo de Cultura Econômica, 1999.686 p.

DRAFT INTERNATIONAL COVENANT ON ENVIRONMENT AND DEVELOPMENT. Environmental Policy and Law Paper. New York, n 31, rev. 2. 2004.

DUNOFF, Jeffrey L.; TRACHTMAN, Joel P. The law and economics of humanitarian law violations in internal conflict. American Journal of International Law. Vol. 93, $\mathrm{n}^{\circ} 2$. Apr. 1999.

FARIA, GuiomarT. Estrella. A interpretação econômica do direito. Porto Alegre: Livraria do Advogado, 1994. $111 \mathrm{p}$.

FAURE. Michael G. Environmental regulation. Publicado em: Encyclopedia of law and economics. Organizado por: BOUCKAERT, Boudewijn; DE GEEST, Gerrit. Cheltenham: Edward Elgar, 2000. 1094 p.

FRADERA, Véra Jacob de. Breves notas sobre a elaboração de plano de trabalho escrito el ou exposição oral. Porto Alegre: UFRGS, 2003. Texto aula.

GROOSMAN, Britt. Pollution tax. Publicado em: Encyclopedia of law and economics. Organizado por: BOUCKAERT, Boudewijn; DE GEEST, Gerrit. Cheltenham; Edward Elgar, 2000. 1094 p.

HACKETT. Steven C. Environmental and natural resources economics. Armonk: M. E. Sharpe, $1998.327 \mathrm{p}$.

HUNTER, David; SALZMAN, James; ZAELKE, Durwood. International environmental law and policy. $2^{\mathrm{a}} \mathrm{ed}$. New York: Foundation Press, 2002.

LOBATO GÓMEZ, Jesus Miguel. Elaboración de estúdios monográficos, el plan de trabajo. Porto Alegre: UFRGS, 2003. Texto aula.

MARCONI, Marina de Andrade. Metodologia científica para o curso de direito. $2^{a}$ ed. São Paulo: Editora Atlas, 2001.

MARGULIS, Sérgio (org.). Meio ambiente, aspectos técnicos e econômicos. $2^{\mathrm{a}}$ ed. Brasília: IPEA, 1996.

MAY, Peter H. (org.). Economia do meio ambiente. Rio de Janeiro: Editora Campus, 2003.

MEDEMA, Steven G.; ZERBE Jr., Richard O. The coase theorem. Publicado em: Encyclopedia of law and economics. Organizado por: BOUCKAERT, Boudewijn; DE GEEST, Gerrit. Cheltenham: Edward Elgar, 2000. 1094 p. 
MERCURO, Nicholas; MEDEMA, Steven G. Economics and the law: from Posner to postmodernism. Princeton: Princeton University Press, 1997. 235 p.

MICELI, Thomas F. Economics of the law. Oxford: Oxford University Press, 1997. 235 p.

MUSGRAVE, Richard A; MUSGRAVE, Peggy B. Finanças Públicas, teoria e prática. Tradução: Carlos Alberto Primo Braga. São Paulo: Editora da Universidade Federal de São Paulo, 1980.673 p.

NICOLAISEN, Joa; DEAN, Andrew; HOELLER, Peter. Economics and the environment: a survey of issues and police options. OECD Economics Studies. Vol. 16. Spring, 1991.

NUNES, Cleucio Santos. Direito tributário e meio ambiente. São Paulo: Dialética, 2005. $207 \mathrm{p}$.

OCDE. OECD environmental outlook (2020). Paris, OECD publications service, 2001. Disponível em: <http://www.oecd.org>. Acesso em: 12 mai. 2005.

The OECD environment programme (2005-2006). Paris, OECD publications service, 2002. Disponivel em: <http://www.oecd.org>. Acesso em: 12 mai. 2005.

Environmentally related taxas in OECD countries - Executive summary. Disponível em: <http://www.oecd.org>. Acesso em: 12 mai. 2005.

PEARCE, David W; TURNER, Kerry R. Economics of natural resources and the environment. Baltimore: Jonhs Hopkins University Press, 1990.378 p.

PHILIPPI Jr, Arlindo; ALVES, Alaor Caffé (org.). Curso interdisciplinar de direito ambiental. Barueri: Editora Manole, 2005.

PINDYCK, Robert S.; RUBINFELD, Daniel L. Microeconomia. $4^{2}$ ed. São Paulo: Makron, 1999.

POSNER, Richard. El análisis económico del derecho. Tradução: Eduardo L. Suárez. México: Fondo de Cultura Económica, 2000.682 p.

ROEMER, Andrés. Introducciòn al anàlisis econômico del derecho. México: Fondo de Cultura Econômica, 1994.

SHAVELL, Steven. Foundations of economic analysis of law. Cambridge: Harvard University Press, 2004.737 p.

UNEP. Global Environment Outlook (GEO 1). Disponível em: <http://www.unep.org>. Acesso em: 17 mai. 2005.

VELJANOVSKI, Cento. A economia do direito e da lei. Rio de Janeiro: Instituto Liberal, 1994. $121 \mathrm{p}$. 